\title{
Evaluation of CERES-Rice Model in Simulation of Rice Growth under Constraint Irrigation and Nitrogen Fertilizer Conditions
}

\section{Mojtaba Mirakhori', BahramMirshekari', Ebrahim Amiri', Farzad Paknejad ${ }^{3}$, Mehrdad Yarnia ${ }^{1}$}

${ }^{1}$ Department of Agronomy and Plant Breeding, Tabriz Branch, Islamic Azad University, Tabriz, Iran

${ }^{2}$ Department of Agronomy, Islamic Azad University, Lahijan Branch, Iran

${ }^{3}$ Department of Agronomy and Plant Breeding, Islamic Azad University, Karaj Branch, Iran

Study Area: Rasht, Iran

Coordinates:37 $16^{\prime} 51^{\prime \prime} \mathrm{N}$; $49^{\circ} 34^{\prime} 59^{\prime \prime} \mathrm{E}$

Key words: Intermittent irrigation,

\begin{abstract}
CERES-Rice model was used to evaluate the effect of nitrogen fertiliser and irrigation on the growth of rice in Iran. To simulate the response function in a split plot experiment, a randomised complete block design with three replications was conducted. Three irrigation treatments (continuous, around 5 and 8 days) were considered as the main factors and the amount of nitrogen in four levels $(0,90,120$ and $150 \mathrm{~kg} \mathrm{~N} / \mathrm{ha})$ as a sub-factor.Based on the evaluation results, it can be concluded that the Ceres-Rice model with the Normalized Root Mean Squared Error (RMSE n) 8 and 6\% with explanation factor, (R2) o.82 - 0.95 to simulate the grain seed rice and also RMSE $\mathrm{n} 10$ and $9 \%$, R2 $0.87-0.85$ to simulate the biological yield, had appropriate accuracy of simulations. Also RMSE $\mathrm{n} 24$ and 16 $\%$, R2 0.76 - 0.87 to simulate the Max LAI, had a moderate accuracy of simulations. These output Evaluation results showed a reasonable estimate of the model as the eff iciency of a model for the grain yield, biological yield and LAI were $0.89,0.75,0.38$ respectively. Thus, these models could be used by researchers as useful tools to support the results under the management of irrigation, improved quality of the consumed water and nitrogen fertiliser in rice.
\end{abstract}

need to accept management expenses to decrease the time and amount of irrigation (Razavipour \& Yazdani, 200o). Also in some cases, the moderate water stress is recommended for better yield (Asadi et al., 2002). Intermittent stress in some physiological periods of rice causes yield increase in compare with permanent flood irrigation, although the increase in stress will result in yield decrease (Kumar et al., 2006; Yang et al., 2003; Ma \& $\mathrm{Lu}, 1990$ ).

Due to different time and place intervals, it is diff icult to determine various levels of yield through farm experiments. Thus, the computer simulation models can be the appropriate tools to estimate the cultivation system and for preparing optimised consumption pattern for the two inputs. Using simulation models is a way to predict and check water balance, growth process simulation, and to study different management stretegies (Amiri et al., 2013).

One of the effective methods to reach these goals, is the use of models for plant growth such as CERES-Rice 
which is a simulation model for rice growth to enable us through calculations of data statistics regarding situation of water, weather, earth, management system, and plant genetic to get the correct results (Amiri et al., 2013). By using this model and utilising its results, we can prevent excess consumption of water and nitrogen fertilisers. By using this model and its results, we can also prevent excess consumption of water and nitrogen fertilisers.

Version 4.5 of CERES-Rice Model Including 20 plant model process-centric and oriented management the development of a variety of agricultural products grown in temperate zones and the tropics are in the world to simulate (Hoogenboom et al., 2003).

CERES-Rice Model represents the arrangement of rice crop growth simulation models, based on recent advances and developments physiological widely to understand the relationship between rice plant and its environment is used (Amiri \& Rezaei, 2013). Singh et al. (2008) simulated Valuation models CropSyst and CERES effect of water and nitrogen on wheat. The results showed that the model CropSyst wheat yield and dry matter more carefully than the simulation model CERES-Wheat stems. Regarding importance of rice cultivation in Guilan province, and necessity to optimized use and economize the agriculture inputs, also the need to use simulation models of plant growth in irrigation management, this experiment has been conducted with the goal to gain the best management for irrigation, nitrogen and evaluation of using CERES- Rice Model for rice yield under various managements of water and nitrogen.

\section{Materials and methods:}

Field experiments: two-years field experiment was conducted at the experimental farm of the Iranian Rice Research Institute in Rasht during the year 2012 to 2013. The experimental design was the split-plot type having a complete randomised block and three replicates. The plot size for the subplots was $15 \mathrm{~m} 2(3 \mathrm{~m} \times 5 \mathrm{~m})$. The main plots were with three irrigation regimes: pond during growth period as a control treatment (I1), 5-day intervals (I2), and 8 -day intervals ( $\mathrm{I}_{3}$ ) and subplot treatments of four levels of $\mathrm{N}$ [no $\mathrm{N}$ application $\left(\mathrm{N}_{1}\right), 90 \mathrm{~kg}\left(\mathrm{~N}_{2}\right), 120 \mathrm{~kg}\left(\mathrm{~N}_{3}\right)$, and 150 $\mathrm{kg}\left(\mathrm{N}_{4}\right)$ ]. In this experiment; urea is the source of Nitrogen. The rice variety '(spring)' was used in the experiment, gives High yield in Guilan province.

Field experiments (Table-1) were carried out on a clay soil tissue ( $9 \%$ sand, $44 \%$ silt, $47 \%$ clay). For the determinations oil characteristics site of this experiment, before transplanting and adding fertilisers several random samples of depth o-30 cm soil obtained and after mixing soil samples to the laboratory for analytical processing of soil physical and chemical tables (1) are shown. Nitrogen fertiliser was given for three times during the study. Total $50 \%$ at the time of transplanting to the field, $25 \%$ at maximum tillering and $25 \%$ of the land was given during bolting. Irrigation was applied 20 days after transplanting Management and to measure the Counters of the water in each plot were used. The continuous irrigation during the growing season was about $5 \mathrm{~cm}$.Sample from each plot was taken to study growth analysis destruction method. Plants harvesting was done on 11-15 August in every year of the experiment. All plots were bonded and separated by 0.5 -m-wide strips of bare soil to avoid lateral movement of water and nutrients among treatments. Measurements from samples collected at the beginning of transplanting in all treatments, crop samples were taken at regular intervals of 10-15 days to determine leaf area index (LAI) and total and panicle biomass in bothyears.

\begin{tabular}{|c|c|c|c|}
\hline \multicolumn{4}{|c|}{ Table 1 .The test resu|ts field soil fertility } \\
\hline Depth Soil- & $0-30(\mathrm{~cm})$ & $P(p \cdot p \cdot m)-$ & 11.9 \\
\hline Tissue- & Clay & O.C (\%)- & 1.32 \\
\hline CEC (meq/10og)- & 31 & Total N (\%)- & 0.13 \\
\hline $\bar{K}(\mathrm{p} \cdot \mathrm{p} \cdot \mathrm{m})-$ & 188 & pH of paste- & 7.2 \\
\hline
\end{tabular}

At flowering time by eliminating two lateral rows and delete rows from the top and bottom, 2 plants per plot were chosen randomly from the middle of each plot to verify the effect. LAI of plants by leaf area meter (Model GA-5 manufactured by OSK Japan) were measured.

CERES - Rice Model Descriptions: version 4.5 of CERES - Rice models were used in this study. Crop development is simulated on the basis of the accumulated thermal time required to reach each phenological stage. In order to evaluat simulation effect of nitrogen fertilizer and irrigation on the growth yield of rice that were used from models which could simulates the plant growth in a day by day and phase by phase basis to get the results. (Amiri et al., 2013).

CERES-Rice Model Input Data: to run the models four sets of data are required as input. Files location, soil, and plant management definition, application and all required parameters of the model range is stated in the manual model (Stöckle et al., 2003). Model inputs for the simulation consists of daily weather information (including maximum and minimum temperature, precipitation and Solar radiation), soil (including physical and chemical properties of each layer), the characteristics Cultivar (viz., growth factors, growth, yield and biomass) and crop management practices (including the use of irrigation and fertilizer, and the culture system (Amiri et al., 2013).

Simulation Model: CERES-Rice Model calculations do with inputs received, from planting to maturity. This model includes Phenological stages, accumulation and partitioning of dry matter, leaf area index, the growth of roots, stems, leaves and seeds as well as soil moisture and 
nitrogen balance, water consumption and water eff iciency and plant nitrogen plant nitrogen and water stress and stress water and nitrogen to simulate the growth and development of plants.

Calibration of the Models: Initially, soil, weather, and irrigation files were prepared alike for all models. After, measurements an estimated crop parameters were inserted in the models. After calibration of the model and determine the optimal coefficients, model validation was performed using the second year of treatment (Table 2). Plant development to the models was according to temperature time $\left({ }^{\circ} \mathrm{C}\right.$-days $)$. Temperature time have been specified for each phonological stage from start to increase the planting stage. The next stage of development starts earlier stage of development that needs to be supplied to the heat. Based on the type of plant phenology important and fundamental steps include emergence, flowering, time of maximum leaf area index, end of flowering, Start filling seed and Physiological maturity.

Table-2: Calibration Results crop parameters Vegetable in CERES-Rice model for Rice simulation in year 2013.

\begin{tabular}{lllllll}
\hline Parameters & $\#$ & EF & $\mathrm{C}_{\mathrm{RM}}$ & $\mathrm{RMSE}_{\mathrm{n}}(\%)$ & $\mathrm{RMSE}$ & $\mathrm{R}^{2}$ \\
BiologyYield & $\mathbf{1 2}$ & 51.0 & 09.0 & 10 & 1340 & 0.87 \\
Yield Seed & $\mathbf{1 2}$ & $\mathbf{0 . 6 7}$ & $\mathbf{0 . 0 3}$ & 8 & 475 & $\mathbf{0 . 8 2}$ \\
\hline LAI & $\mathbf{1 2}$ & $\mathbf{0 . 3 8}$ & $\mathbf{0 . 2 1}$ & $\mathbf{2 4}$ & $\mathbf{1}$ & $\mathbf{0 . 7 6}$
\end{tabular}

Table 3. Validation Results crop parameters Vegetable in Ceres-Rice model for Rice simulation in year 2014 .

\begin{tabular}{lllllll}
\hline Parameters & $\#$ & EF & C $_{\mathrm{RM}}$ & RMSE $_{\mathrm{n}}(\%)$ & RMSE $^{2}$ & $\mathrm{R}^{2}$ \\
BiologyYield & $\mathbf{1 2}$ & $\mathbf{0 . 7 5}$ & 0.06 & 9 & 1121 & 0.85 \\
YieldSeed & $\mathbf{1 2}$ & $\mathbf{0 . 8 9}$ & $\mathbf{0 . 1 1}$ & 6 & 323 & 0.95 \\
\hline LAI & $\mathbf{1 2}$ & $\mathbf{0 . 3 8}$ & $\mathbf{0 . 1 1}$ & 16 & 1 & 0.80
\end{tabular}

\#- Number of samples; EF- mean of Efficiency of Model; $\mathrm{C}_{\mathrm{RM}}$ Coefficient of residual mass; $\mathrm{RMSE}_{\mathrm{n}}$ mean of (\%), normalized root mean square error; $\mathrm{R}^{2-}$ mean of adjusted linear correlation coefficient between simulated and measured values.

Model Evaluation: Several statistical methods were used to compare the simulated and observed results. In this article, we used a combination of graphical analyses and statistical measures to graphically compare the simulated and measured final biomass and yield and LAI. We evaluated model performances using the absolute root mean square error (RMSE) and normalised root mean square error (RMSEn) and CRM (Coefficient of Residual Mass) and (R2) Coefficient of Determination and (EF) effective modelling. RMSE and RMSEn and CRM and R2 and EF characteristics are common tools to test the goodness of fit of simulation models (Pala etal., 1996).

Plant coefficients used in the Ceres - Rice model: P1-610; $\mathrm{P}_{5-420}$; G1-55;G2-0.02; G3-1; G4-1.

\section{Results \& Discussion :}

The crop parameters used in this study are presented in Tables 2 and 3 and Figure 1 \& 2 for Model. Ambient Science (2016)
Validation and Evaluation of model : the model validations were based on the comparison between simulated and observed data for all the treatments except those which were used in model calibration.

Results showed that the average grain yield RMSE in calibration and validation conditions was 475 and $323 \mathrm{~kg}$ per hectare respectively. The average RMSEn of grain yield in calibration and validation conditions were 8 and 6 percent respectively. The amounts of the parameters measured grain yield showed a desirable simulation of this parameter in agriculture season by the model which we can use in irrigation planning and nitrogen-rich fertiliser (Table 2 \& 3 ).

For calibration and validation phases, the amount of CRM excluding maximum LAI, grain yield and dry material in the first year was negative, which showed that the amount of simulation in most treatments was more than the observation amounts. In other words, in most of the treatments the estimated amount of the model was more than the real amounts.

Based Confalonieri \& Bocchi, (2005)'s study on simulation of rice plant yield in North Italy, the RMSE n amplitude of dry material simulated measured for calibration and validation year was 11 to 29 and 10 to 52 percent respectively, and CRM amplitude of dry material simulated measured for calibration and validation year was-0.03 to 0.17 and -0.02 to 0.17 percent respectively. The EF in calibration (first year) conditions maximum, and grain yield and dry material was 0.38 and 0.67 and 0.51 respectively. In addition, the EF in evaluation conditions maximum LAI, grain yield and dry material was 0.38 and 0.89 and 0.75 respectively. According to Mohseni et al., (2008) simulation of this model in different levels of nitrogen was performed on Corn plants, and the EF on calibration and evaluation phases were 0.52 and 0.90 respectively. Additionally, Sadres (2002)'s study on simulation of wheat plant yield by CropSyst model, the amount of RMSE was equal to $0.21 \mathrm{Mg} / \mathrm{ha}$ and the amount of correlation factorwas 0.72 .

The R2 under calibration (first year) conditions maximum LAI, grain yield and dry material was 0.76 and 0.82 and 0.87 respectively. Also the $\mathrm{R}_{2}$ in evaluation conditions maximum LAI and grain yield and dry materials were 0.80 and 0.95 and 0.85 respectively. The relatively high amount of $\mathrm{R} 2$ means low dispersion of data (Amiri et al., 2013).

Results showed that the average RMSE biology yield under calibration and validation conditions are 1340 and $1121 \mathrm{~kg}$ per hectare respectively. The amounts of average RMSEn Biology Yield under calibration and validation conditions arealso 10 and 9 percent respectively. Pala et al., (1996) for performance recognition of the CropSyst model in simulation of dry material production and yield of reaction to the water and nitrogen, studied separate 

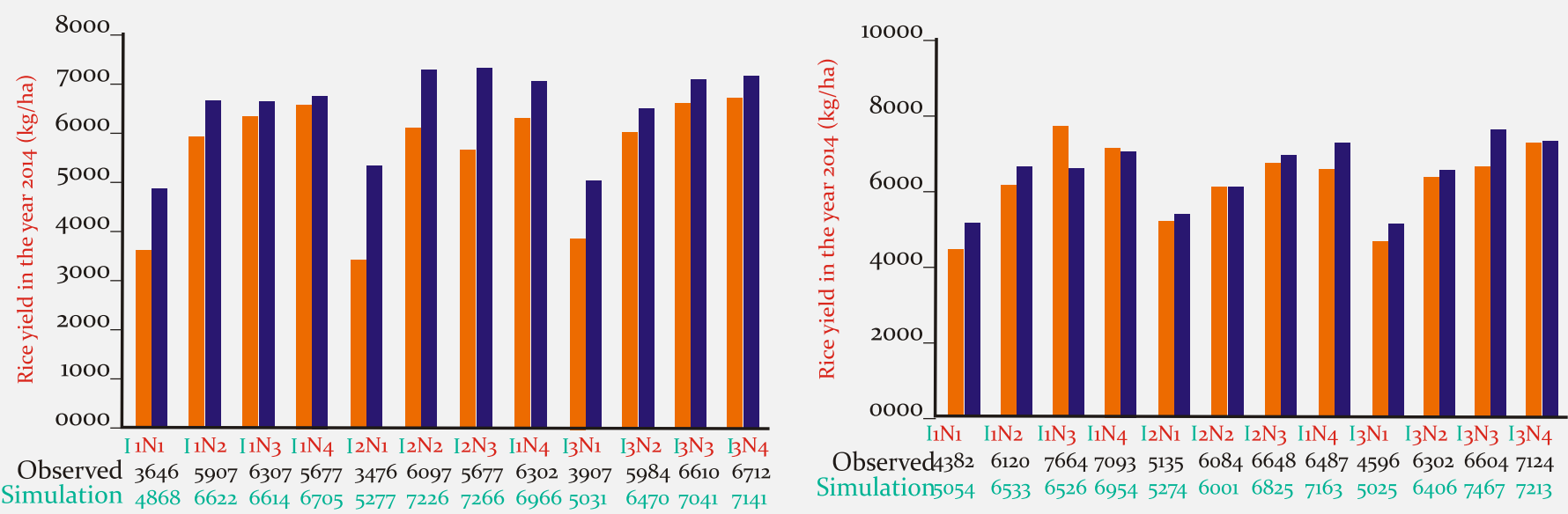

Irrirgation $=\left(I_{3}=8\right.$ perday; $I_{2}=5$ perday; $I_{1}=$ Continuously flooded $)$ and $\mathrm{N}$ fertilizer $\left(\mathrm{N}_{1}=0 ; \mathrm{N}_{2}=90 ; \mathrm{N}_{3}=120 ; \mathrm{N}_{4}=150 ;(\mathrm{Kg} / \mathrm{ha})\right.$

Figure1 \& 2: Amounts Observed and Simulation grain Yield for plant Rice in year 2013 \& 2014.

products in a season under experimental conditions with extensive preparations from dry to full irrigations and from low nitrogen existing on earth to the high level conditions. In these evaluations, the amount of RMSE reported was 0.443 tonnes per hectare.

Results showed that the average RMSE in calibration and validation conditions are 1 and 1 square meters of leaf surface in each square meter of ground level. The amounts of RMSEn for maximum LAI in calibration and validation conditions are 24 and 16 percent respectively. The results showed an acceptable accuracy of this model for simulation of maximum LAI. Moreover, Saadati et al. (2013)'s report on evaluation and simulation of both effect of water and nitrogen on wheat plant, the amount of RMSE for simulation yield in CropSyst model was $0.36 \mathrm{Mg} / \mathrm{ha}$. The amounts of parameters measured indicate Medium simulation of this parameter along agriculture season by this model which can be used for planning of rice irrigation and nitrogen fertiliser. The existence of some weather parameters such as wind speed and carbon dioxide changes in the farm which are not located in the model (the model anticipates grain yield according to other climate parameters) may also be another reason for a decline in foresight accuracy by the model (Kiani, 2001).

Changes in the amount of simulated grain yield by Ceres-Rice Model for the first and second year are shown in figures (1) and (2). The minimum amount of grain yield was under no use of nitrogen fertiliser condition, and maximum yield was in nitrogen treatment condition of 120 $\mathrm{kg}$ nitrogen per hectare and intermittent irrigation of once per 8 days. The results showed that by increasing nitrogen consumption, the grain yield would rise. The model also showed fluctuations in simulated grain yield clearly.

The amount of grain yield would be elevated by adding more nitrogen in irrigation management, but in higher levels of nitrogen ( 150 and $120 \mathrm{~kg} / \mathrm{ha}$ ), a slight raise would be shown. On the other hand, the grain yield would be reduced under flood irrigation conditions. Besides, by changing irrigation model from flood to intermittent treatments of once per 5 or 8 days, simulated grain yield would show a minimal escalation; which indicates that the amount of nitrogen consumption is more than the nutrition needs of spring type rice in this research.

Irrigation change from flood to intermittent will reduce hydrostatic pressure of water at the ground level which causes reduction of water loss through leakage and deep percolation (Bouman et al., 2007).

\section{Conclusion:}

The CERES-Rice Model was sufficiently accurate in the simulation of yield underwater-saving and crop density conditions for our study site. In the present study, the Ceres-Rice Model crop simulation model was calibrated validated in a humid region of Iran. In general, given the negligible difference between observed and simulated values performance can be concluded that this model might be useful as a model simulated the effect of water and nitrogen management on yield estimates used.

\section{Acknowledgements:}

The authors are grateful to the Rasht Rice Research Institute, for providing resources and for providing facilities.

\section{References:}

Amiri E. \& Rezaei M. (2013): Evaluation of Water Balance Components and WaterProductivity of RiceUnder Interval Irrigation and Nitrogen Fertilizer Conditions. Iranian J. lrrig. Drainage.4(6):306-315.

Amiri, E., Rezaie, M., Aval, M.B., Soufizadeh, S. \& Banayan M. (2013): Calibration and Evaluation of CERES Rice Modelunder Different Nitrogen- and Water-Management Options in Semi-Mediterranean Climate Condition Commun. Soil Sci. Plant Analysis, 44:1814-1830, 2013

Bouman, B.A.M., Peng, S., Castaneda, A.R. \& Visperas, R.M. (2005): Yield and water use of irrigated tropical aerobic rice systems. Agr. Water Manag., 74: 87-105. 
Bouman, B.A.M., Fenga, L., Tuonga, T.P., Guoan, Lu, Wangc, H. \& Fenge, Y. (2007): Exploring options to grow rice using less water in northern China using a modelling approach-II. Quantifying yield, water balance components and water productivity. Agr. Water Manage., 88(1-3):23-33.

Confalonieri, R. \& Bocchi, S. (2005): Evaluation of CropSyst for simulating the yield of flooded rice in northern Italy. Europ. J. Agronomy. 23:315-326.

Hoogenboom, G., Jones, J.W., Porter, C.H., Wilkens, P.W., Boote, K.J., Batchelor, W.D., Hunt, L.A. \& Tsuji, G.Y. (2003): Decision Support System for Agrotechnology Transfer Ver. 4.o. Vol.-1: Overview. University of Hawaii, Honolulu, HI, 169p.

Kiani, E. (2001): CERES-Wheat climate model evaluation in different places in the province. Master's thesis of Agriculture. Faculty of Agriculture. Ferdowsi University of Mashhad. 67p.

Kumar, R., Sarawgi, A.K., Ramos, C., Amarante, S.T., Ismail, A.M. \& Wade, L.J. (2006): Partitioning of dry matter during drought stress in rainfed lowland rice. Field Crops Res., 96: 455-465.

Ma, Y.F \& Lu, D.Z. (1990): Effect of irrigation methods on senescence and physiological activities in hybrid rice after heading. Chin. J. RiceSci. 4(2): 56-62.

Mohseni, M., Montazer, A. \& Rahimi, A. (2008): The evaluationmodelof plantCropSystInthesimulation, the combined effect of water and nitrogenon yield and water productivity of wheat. Iran. J. Sci. Irri. Drain.,3(1):113-125.

Pala, M., Stockle, C.O. \& Harris, H.C., (1996): Simulation of durum wheat (Triticumturgidum ssp. durum) growth under different water and nitrogen regimes in a Mediterranean environment using CropSyst. Agric. Syst., 51(21):147-163.
Pirmoradian, N., Sepaskhah, A.R., Maftoun, M. (2004): Effects of water-saving irrigation and nitrogenfertilization on yield and yield components of rice (Oryza sativa L.). Plant Prod. Sci.,7(3):337-346.

Razavipour, T., Yazdani, M. \& Kavosi, M. (2000): The effects of water stress in different growing stage onrice yield. VI National Conference on Soil Science. Tehran. Pp 613-614.

Saadati, Z., Pirmoradian, N. \& Rezaei, M. (2013): Yield Response Simulation of Two Local Rice Varieties to Irrigation Management Using CropSyst Model .J.Water Soil Sci., 17 (64): 69-81.

Sadras, V.O. (2002): Interaction between rainfall and nitrogen fertilisation of wheat in environments prone to terminal drought economic and environmental risk analysis. Field Crops Res. 77(2-3):201-215.

Singh, A.K., Tripathy, R. \& Chopra, U.K. (2008): Evaluation of CERES-Wheat and CropSyst models for water-nitrogen interactions in wheat crop. Agricul. Water Manag., 95(7): 776-786.

Stöckle, C.O., Donatelli, M., \& Nelson, R. (2003): CropSyst, a cropping systems simulation model. Europ. J. Agronomy, 18: 289-307.

Yang, H., Zhang, X. \& Zehnder, A.J.B. (2003): Water scarcity, pricing mechanism and institutional reform in northern China irrigated agriculture. Agric. Water Manage., 61:143-161. 